\title{
Progress in Cell Grafting Therapy for Temporal Lobe Epilepsy
}

\author{
Ashok K. Shetty \\ Published online: 4 September 2011 \\ (C) The American Society for Experimental NeuroTherapeutics, Inc. (Outside the U.S.) 2011
}

\begin{abstract}
Temporal lobe epilepsy (TLE), exemplified by complex partial seizures, is recognized in $\sim 30 \%$ of epileptic patients. Seizures in TLE are associated with cognitive dysfunction and are resistant to antiepileptic drug therapy in $\sim 35 \%$ of patients. Although surgical resection of the hippocampus bestows improved seizure regulation in most cases of intractable TLE, this choice can cause lasting cognitive deficiency and reliance on antiepileptic drugs. Thus, alternative therapies that are proficient in both containing the spontaneous recurrent seizures and reversing the cognitive dysfunction are needed. The cell transplantation approach is promising in serving as an adept alternate therapy for TLE, because this strategy has shown the capability to curtail epileptogenesis when used soon after an initial precipitating brain injury, and to restrain spontaneous recurrent seizures and improve cognitive function when utilized after the occurrence of TLE. Nonetheless, this treatment needs further advancement and rigorous evaluation in animal prototypes of chronic TLE before the conceivable clinical use. It is especially vital to gauge the efficacy of distinct donor cell types, such as the hippocam-
\end{abstract}

Electronic supplementary material The online version of this article (doi:10.1007/s13311-011-0064-y) contains supplementary material, which is available to authorized users.

A. K. Shetty $(\bowtie)$

Institute for Regenerative Medicine, Texas A\&M Health Science

Center at Scott \& White,

Department of Molecular and Cellular Medicine,

Temple, TX 76502, USA

e-mail: shetty@medicine.tamhsc.edu

A. K. Shetty

Research Service, Central Texas Veterans Health Care System,

Temple, TX 76502, USA

\section{A. K. Shetty}

Department of Surgery (Neurosurgery) and Research Service,

Duke University and Durham VA Medical Centers,

Durham, NC 27710, USA pal precursor cells, $\gamma$-aminobutyric acid-ergic progenitors, and neural stem cells derived from diverse human sources (including the embryonic stem cells and induced pluripotent stem cells) for longstanding seizure suppression using continuous electroencephalographic recordings for prolonged periods. Additionally, the identification of the mechanisms underlying the graft-mediated seizure suppression and improved cognitive function, and the development of apt grafting strategies that enhance the anti-seizure and procognitive effects of grafts will be necessary. The goal of this review is to evaluate the progress made hitherto in this area and to discuss the prospect for cell-based therapy for TLE.

Keywords Cell therapy for epilepsy · Chronic epilepsy · Complex partial seizures - GABA-ergic transplants . Hippocampal neurogenesis · Neural stem cell grafts . Spontaneous recurrent seizures $\cdot$ Temporal lobe epilepsy

$\begin{array}{ll}\text { Abbreviations } \\ \text { AEDs } & \text { antiepileptic drugs } \\ \text { BDNF } & \text { brain-derived neurotrophic factor } \\ \text { BNC } & \text { BDNF, NT-3 and caspase inhibitor } \\ \text { CA1 } & \text { cornu ammonis 1 } \\ \text { CA3 } & \text { cornu ammonis } 3 \\ \text { DG } & \text { dentate gyrus } \\ \text { EEG } & \text { electroencephalographic } \\ \text { ES cells } & \text { embryonic stem cells } \\ \text { FC } & \text { FGF-2 and caspase inhibitor } \\ \text { FDA } & \text { food and drug administration } \\ \text { fEPSP } & \text { field excitatory postsynaptic potential } \\ \text { FGF-2 } & \text { fibroblast growth factor-2 } \\ \text { FHC } & \text { fetal hippocampal cell } \\ \text { GABA } & \gamma \text {-aminobutyric acid } \\ \text { GAD-67 } & \text { glutamic acid decarboxylase-67 } \\ \text { GDNF } & \text { glial-cell derived neurotrophic factor } \\ \text { ICV KA } & \text { intracerebroventricular kainic acid } \\ \text { IPI } & \text { initial precipitating injury }\end{array}$

Abbreviations

AEDs brain-derived neurotrophic factor

$\mathrm{BNC}$

CA1 BDNF, NT-3 and caspase inhibito cornu ammonis 1 cornu ammonis 3 dentate gyrus electroencephalographic FGF-2 and caspase inhibitor food and drug administration fEPSP field excitatory postsynaptic potential FGF-2 fibroblast growth factor-2 FHC fetal hippocampal cell GABA $\quad \gamma$-aminobutyric acid GAD-67 glutamic acid decarboxylase-67 GDNF IPI initial precipitating injury 


$\begin{array}{ll}\text { iPS cells } & \text { induced pluripotent stem cells } \\ \text { KA } & \text { kainic acid } \\ \text { MGE } & \text { medial ganglionic eminance } \\ \text { MGE-NSC } & \text { medial ganglionic eminence neural stem cell } \\ \text { NPY } & \text { neuropeptide Y } \\ \text { NSCs } & \text { neural stem cells } \\ \text { NT-3 } & \text { neurotrophin-3 } \\ \text { PV } & \text { parvalbumin } \\ \text { SE } & \text { status epilepticus } \\ \text { SRS } & \text { spontaneous recurrent seizures } \\ \text { SVZ-NSCs } & \text { subventricular zone neural stem cells } \\ \text { TLE } & \text { temporal lobe epilepsy } \\ \text { VNS } & \text { vagal nerve stimulation }\end{array}$

\section{Introduction}

Epilepsy affects more than 50 million people worldwide and temporal lobe epilepsy (TLE) is the leading and the most difficult to treat type of epilepsy. Although the etiology of TLE is unknown in most cases, it is typically seen after an initial precipitating injury (IPI), such as status epilepticus (SE), traumatic brain injury, tumors, meningitis, and encephalitis [1-3]. TLE is seen in more than $30 \%$ of epilepsy patients and is typified by multiple hippocampal abnormalities $[4,5]$. These include variable loss of principal excitatory neurons in different subfields (also referred to as hippocampal sclerosis), a substantial reduction in the numbers of diverse subclasses of inhibitory $\gamma$-aminobutyric acid positive (GABA-ergic) interneurons, an aberrant synaptic reorganization in the dentate gyrus, altered expression of neurotransmitter receptors and ion channels, hippocampal hyperexcitability due to an increase in the overall excitatory tone vis-à-vis the inhibitory function, spontaneous complex partial seizures (referred to as spontaneous recurrent seizures [SRS] in animal models of TLE) originating mostly from the hippocampus, and impairments in hippocampal-dependent cognitive function and mood [6-16]. Although a lifelong intake of antiepileptic drugs (AEDs) is effective for restraining seizures in most patients, a sizeable fraction $(>35 \%)$ of patients develop intractable TLE [17]. This is typified by sustained occurrences of SRS, despite the intake of AEDs, which submits these patients to the risk of irrepressible seizure activity. Furthermore, long-term AED therapy has side effects, and most TLE patients have memory and mood dysfunction that are not alleviated with AEDs [5, 13, 18, 19].

The treatment choices that are alternative to the intake of AEDs for TLE are inadequate. The ketogenic diet, effective for diminishing seizures in children with refractory epilepsy, has shown limited capability for remedying adult patients and this diet is challenging to persevere for protracted periods $[20,21]$. Interventional treatment strategies comprise the surgical resection of the hippocampus and vagus nerve stimulation (VNS). Although the resection surgery intended to eliminate the seizure-generating sector is beneficial for restraining seizures in nearly two thirds of patients with intractable epilepsy, only a subgroup of patients with drug-resistant epilepsy is eligible for surgery, because the seizure-generating zone is not well-delineated and the surgical resection of the hippocampus often leads to significant cognitive impairments, loss of viable tissue, and the possibility of continuing dependence on AEDs [22]. On the other hand, VNS therapy decreases seizure frequency by $\sim 50 \%$ in only one third of epilepsy patients [23]. Therefore, novel therapies that are efficacious for both preventing and diminishing SRS, and reversing memory and mood dysfunction in TLE are needed. In this context, cell transplantation approach has promise in serving as an adept alternate therapy for TLE. This is because this strategy has shown the capability to curb epileptogenesis (the succession that modifies a normal brain region into an epileptic precinct) when employed soon after an IPI, and to contain SRS when utilized after the occurrence of TLE in pre-clinical studies [24-30]. Because the seizuregenerating zone and the associated cell loss are mainly localized to the hippocampus in most cases, TLE appears to be good candidate to treat it with the cell transplantation approach.

The goal of this review is to evaluate the progress made hitherto in this area and to discuss the perspective for cellbased therapy for TLE. The first part of this review discusses the prospects for preventing or minimizing SRS through intracerebral grafting of distinct donor cell types (e. g., hippocampal precursor cells, GABA-ergic progenitors, and neural stem cells [NSCs] from diverse sources) at early time points after an IPI in the hippocampus. The next part of this review confers the efficacy of diverse cell grafts for restraining SRS and easing cognitive dysfunction when used after the occurrence of chronic TLE. Additionally, critical issues that need to be resolved before initiating the clinical use of cell grafting therapy for TLE are discussed.

\section{Cell Therapy for Restraining Epileptogenesis Shortly} after an Initial Precipitating Injury

The ability of the adult hippocampus for self-repair after injury is limited, despite the fact that multipotent and selfrenewing NSCs persist in this region and neurogenesis in the dentate gyrus of the hippocampal formation continues all through life [27, 31, 32]. As a consequence, spontaneous replacement of lost neurons with region-specific new neurons does not occur adequately in the adult hippocampus after injury or disease. In addition, the plasticity of 
surviving neurons and the circuitry of a fraction of newly born dentate granule cells after the injury appear to be detrimental toward normalizing the hippocampal function after injury [24, 27, 33, 34]. These issues have provided an impetus for replacing lost neurons through grafting of fresh hippocampal precursor cells obtained from the fetal brain or NSCs/neuronal progenitors expanded from diverse sources in animal models of hippocampal injury and TLE [25, 2730]. Grafting of specific post-mitotic hippocampal precursor cells shortly after hippocampal injury or SE has significance, because such an approach has promise for replacing the lost neurons, as well as facilitating the reconstruction the disrupted hippocampal circuitry $[14,24$, $25,35,36]$. Grafting of NSCs, on the other hand, is attractive because of the possibility that immature NSCs to the injured area may secrete a multitude of beneficial neurotrophic and anticonvulsant factors and may also strengthen the inhibitory neurotransmission through addition of new GABA-ergic neurons to the hippocampal circuitry [37]. Apt reorganization of the damaged host hippocampal circuitry by neural cell grafts may also inhibit or reverse the aberrant circuitry formation observed after hippocampal injury or SE $[14,36]$. Studies that addressed these issues using cell grafts in models of TLE are discussed as follows.

\section{Efficacy of Fetal Hippocampal Cell Grafts in a Unilateral Hippocampal Injury Model of TLE}

A unilateral hippocampal injury in adult rats induced through an intracerebroventricular kainic acid administration was initially used as a model of TLE for grafting studies. Because of a substantial loss of CA3 pyramidal neurons and a significant loss of CA1 pyramidal neurons, this prototype is believed to be closer to the unilateral hippocampal sclerosis typically seen in TLE. Several studies have examined the usefulness of fetal hippocampal cell grafts placed shortly after injury for facilitating an apt reconstitution of the damaged hippocampal circuitry and suppressing many epileptogenic changes [14, 24, 25]. Quantification of the graft cell survival revealed that survival of grafted cells in the injured adult hippocampus depends on the specificity of donor cells to the region of grafting, which was evidenced by a better survival of hippocampal-derived fetal neurons than fetal neurons derived from nonspecific regions, such as the striatum [38]. The studies also showed that the receptivity of the injured hippocampus for survival of even the specific cell grafts decreases with time after injury [39]. However, the fraction of grafted cells that survived the first month of grafting was shown to persist even after a year of grafting in this model [40]. Analyses of graft-host connectivity revealed extensive axonal growth from fetal CA3 cell grafts into the deafferented inner molecular layer of the dentate gyrus and the strata oriens and radiatum of the CA1 subfield (Fig. 1) [14]. These cell grafts also established robust commissural and septal projections [35].
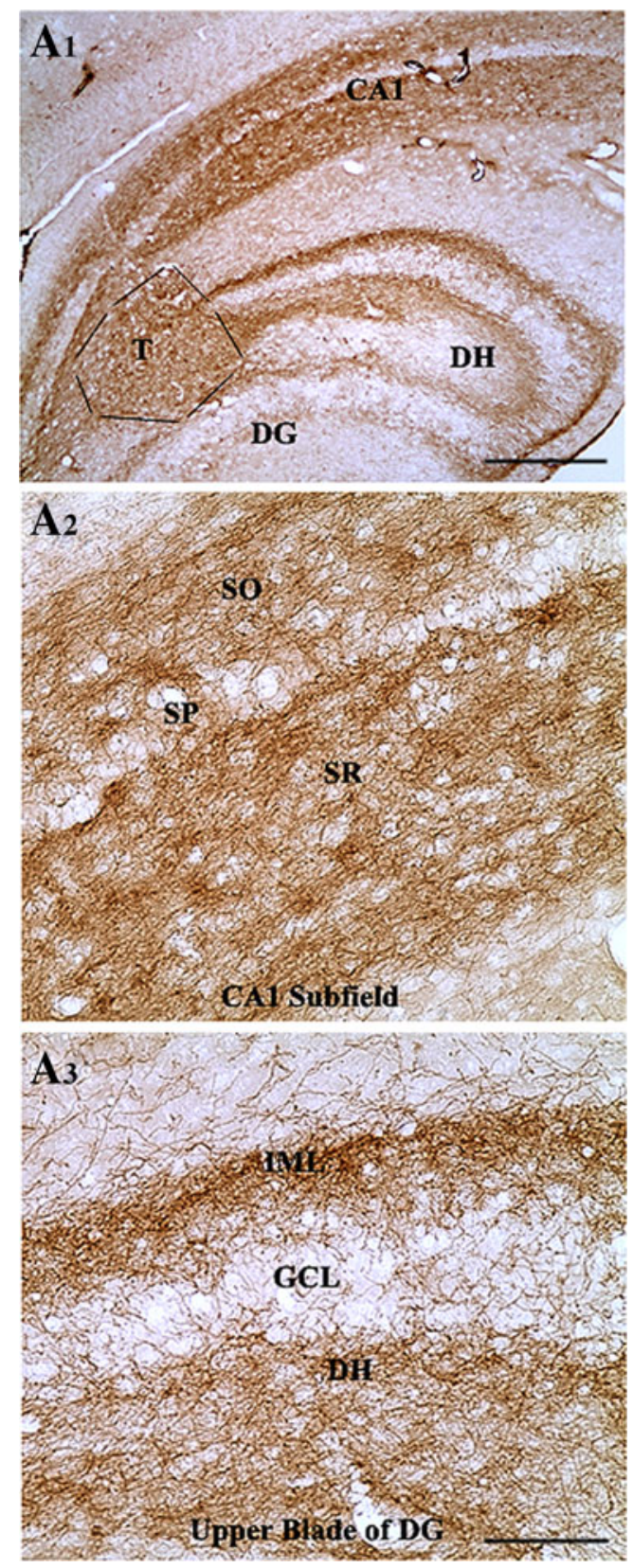

Fig. 1 The pattern and extent of axon growth from a mouse CA3 cell graft in the host rat hippocampus at 30 days after grafting, visualized with M6 immunostaining (A1). The graft axon growth into the injured hippocampus is highly conspicuous in the strata oriens (SO) and radiatum (SR) of the $\mathrm{CA} 1$ subfield (A2), the inner molecular layer (IML) of the dentate gyrus (DG) (A3), and the dentate hilus (DH) (A3). GCL = granule cell layer; $\mathrm{T}=$ transplant; $\mathrm{SP}=$ strata pyramidale. Scale bars $=$ (A1) $500 \mu \mathrm{m}$; (A2, A3) $100 \mu \mathrm{m}$. (Figure reproduced with modifications from (Fig. 4), Shetty et al., J Neurosci 2005;25:8391-8401) 
Furthermore, the fetal cell grafts comprising CA3 neurons promoted several antiepileptogenic effects. First, they were efficient for normalizing the hippocampal injuryinduced depletions in the numbers of GABA-ergic interneurons (Fig. 2), likely through reinnervation of the deafferented and GAD-67 deficient interneurons [8]. This effect is considered beneficial because reactivation of interneurons could ease the loss of functional inhibition and hyperexcitability observed in the injured/epileptic hippocampus. Second, these grafts can greatly diminish the overall extent of the aberrant mossy fiber sprouting into the dentate supragranular layer (a type of synaptic reorganization that occurs after hippocampal injury in epilepsy models and TLE) (Fig. 3) on a long-term basis [14]. Additionally, sprouts of host mossy fibers from the host principal mossy fiber bundle invaded and densely innervated the larger CA3 pyramidal neurons within grafts (Fig. 3). It appeared that the suppression of aberrant mossy fiber sprouting depended on a numerically dense innervation of more appropriate postsynaptic targets within the grafts (i.e., CA3 neurons) than the abnormal vacant synaptic sites in the dentate supragranular layer. Suppression of this sprouting is considered useful because the aberrantly sprouted mossy fibers are generally believed to contribute toward the generation and propagation of seizures in TLE [14, 41, 42]. Third, grafting of fetal CA3 cells can restore the injury-induced loss of the calciumbinding protein calbindin in both dentate gyrus and the CA1 subfield, which is likely a result of restitution of the disrupted circuitry previously mentioned. Because the loss of the calbindin after hippocampal injury is linked to hyperexcitability [43], restoration of calbindin expression with CA3 cell grafting indirectly implied that specific cell

Fig. 2 Comparison of the distribution of GAD-67-positive interneurons in the dentate gyrus (A1-A4) and the CA1 subfield (B1-B4) of an intact control hippocampus (A1, B1), a kainic acid (KA)-lesioned hippocampus (A2, B2), a KA-lesioned hippocampus receiving mixed hippocampal cell graft (A3, B3), and a KA-lesioned hippocampus receiving CA3 cell graft (A4, B4). Note that, in comparison to the intact hippocampus, GAD-67-positive interneuron density appears decreased in both dentate gyrus and CA1 subfield of the lesion-only hippocampus (A2, B2). In contrast, both of these regions in the lesioned hippocampus receiving either mixed hippocampal (A3, B3) or CA3 cell grafts (A4, B4) exhibit interneuron density that is closer to the intact hippocampus. $\mathrm{DH}=$ dentate hilus; $\mathrm{GCL}=$ granule cell layer; $\mathrm{ML}=$ molecular layer; $\mathrm{SO}=$ stratum oriens; $\mathrm{SP}=$ stratum pyramidale; $\mathrm{SR}=$ stratum radiatum. Scale $\mathrm{bar}=100 \mu \mathrm{m}$. The bar chart compares GAD-67+ interneuron density in the dentate gyrus between different groups. Compared to the intact control hippocampus, interneuron density in the lesion-only hippocampus is reduced in all 3 layers of the dentate gyrus $(p<0.05)$. In contrast, interneuron density in the dentate gyrus of lesioned hippocampi receiving grafts of either mixed hippocampal or CA3 cells is comparable with that in the intact control hippocampus $(p>0.05)$ and significantly greater than the lesion-only hippocampus $(p<0.05)$. Values are means \pm SEM. (Figure reproduced with modifications from (Fig. 4), Shetty and Turner, J Neurosci 2000;20:8788-8801) grafting can ameliorate the injury-induced hyperexcitability in the hippocampus. Overall, it was suggested in the previous series of studies that specific cell grafting can restore the damaged circuitry, as well as minimize several epileptogenic changes in the injured/epileptic host hippocampus. However, the effect of grafts was not directly examined on the extent of SRS occurring at extended time points after injury, as behavioral SRS are typically minimal or inconsistent in this model. Long-term electroencephalo-
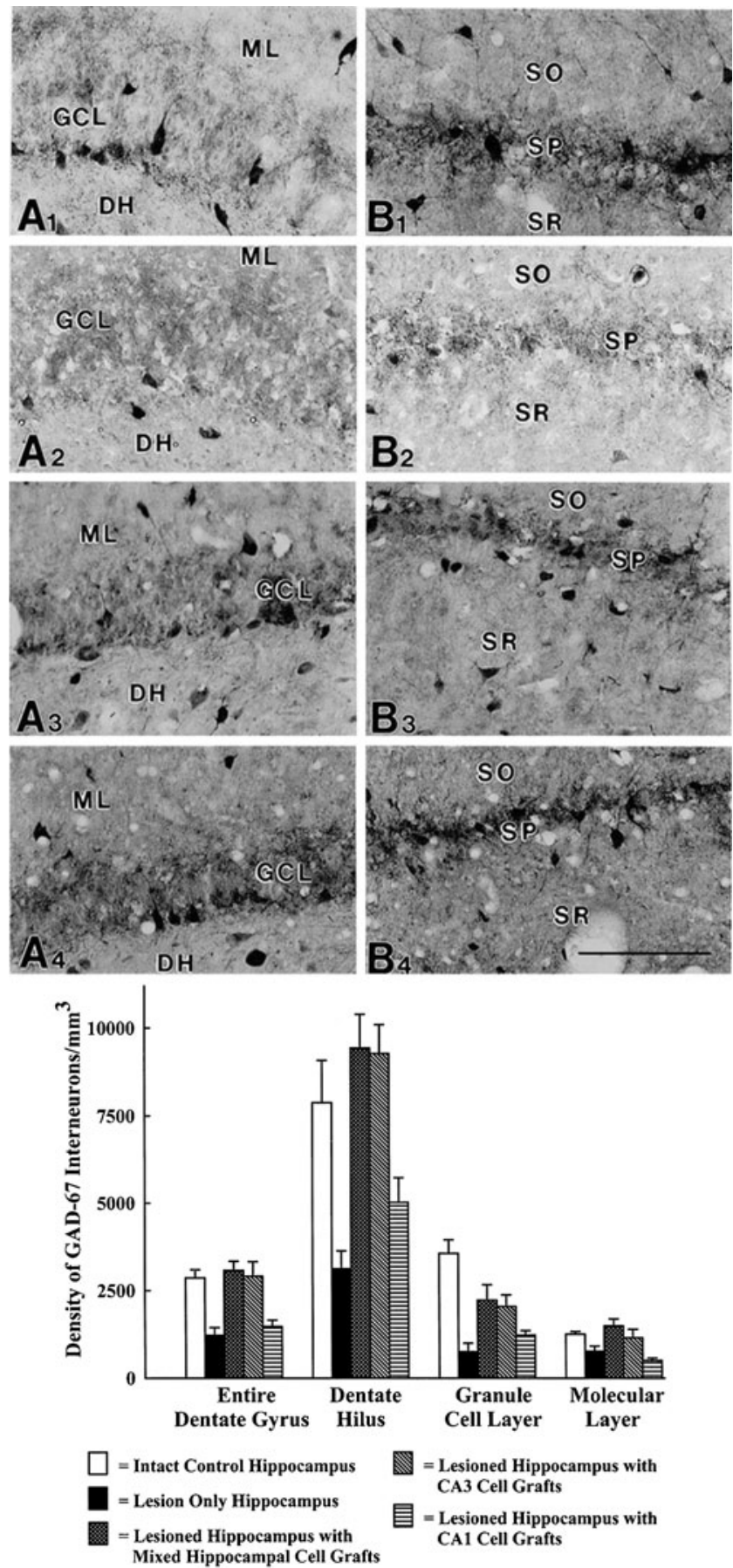


\section{Intact Hippocampus (Hps) and Kainic acid (KA) Lesioned Hps}
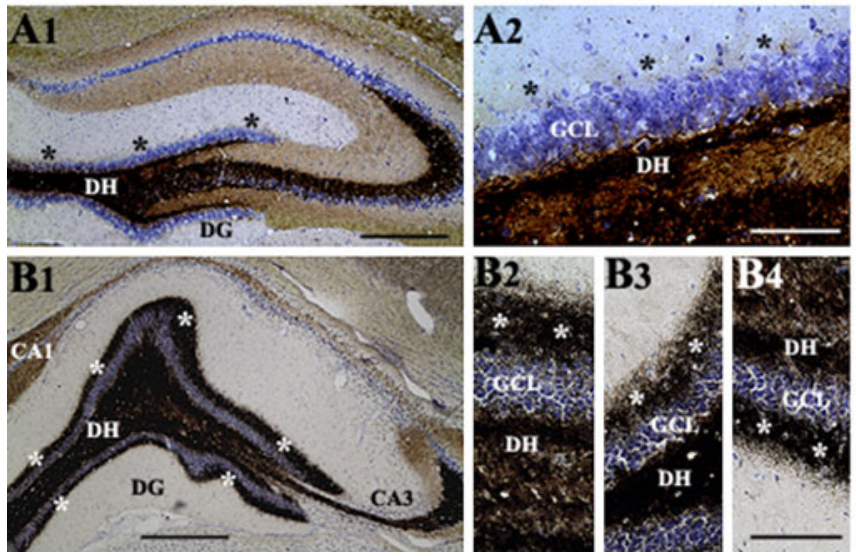

Fig. 3 Extent of the mossy fiber sprouting in the dentate gyrus of control, lesion-only, and lesioned, grafted animals. (A1) Example of the intact control hippocampus. (A2) Enlarged view of the upper blade of the dentate gyrus (A1), which demonstrates the absence of aberrant mossy fiber sprouting in the dentate supragranular layer (DSGL) (black asterisks). (B1) Example of the lesion-only hippocampus at 12 months after injury, and (B2-B4) regions of the upper blade, the crest, and the lower blade of the dentate gyrus (B1) demonstrate very robust aberrant mossy fiber sprouting into the DSGL (white asterisks). (C1) An example of the lesioned hippocampus receiving (CA3) cell grafts at 4 days after injury and analyzed at 1 year after grafting. The transplant (boundaries depicted by interrupted lines) is located in the

graphic (EEG) recordings will be needed in the future to fully evaluate the usefulness of fetal hippocampal CA3 cell grafts for preventing SRS in this unilateral injury model of TLE.

\section{Ability of Fetal Hippocampal Cell Grafts for Diminishing SE-Induced SRS}

To ascertain whether an early grafting after SE would prevent or diminish the occurrence of chronic TLE typified by SRS and cognitive dysfunction, grafting studies were performed in an SE prototype of TLE, induced through graded intraperitoneal injections of kainic acid [44, 45]. Because of the partial bilateral loss of both CA1 and CA3 pyramidal neurons in this model, mixed fetal hippocampal cell grafts were placed bilaterally into the hippocampi at 4 days post-SE. The results revealed that such cell grafting is effective for considerably attenuating chronic epilepsy on a long-term basis. The hippocampal cell grafts were found to be efficient for suppressing the frequency ( $\sim 90 \%$ reduction) and duration ( $\sim 75 \%$ reduction) of behavioral SRS for prolonged periods [45]. A greatly diminished SRS in the grafted hippocampus was also revealed through direct EEG recordings at 6-months postgrafting. Histological analyses revealed robust long-term survival (equivalent to $\sim 67 \%$ of injected cells) and apt differentiation of grafted
KA-Lesioned Hps Receiving CA3 Cell Grafts at 4 days Post-injury

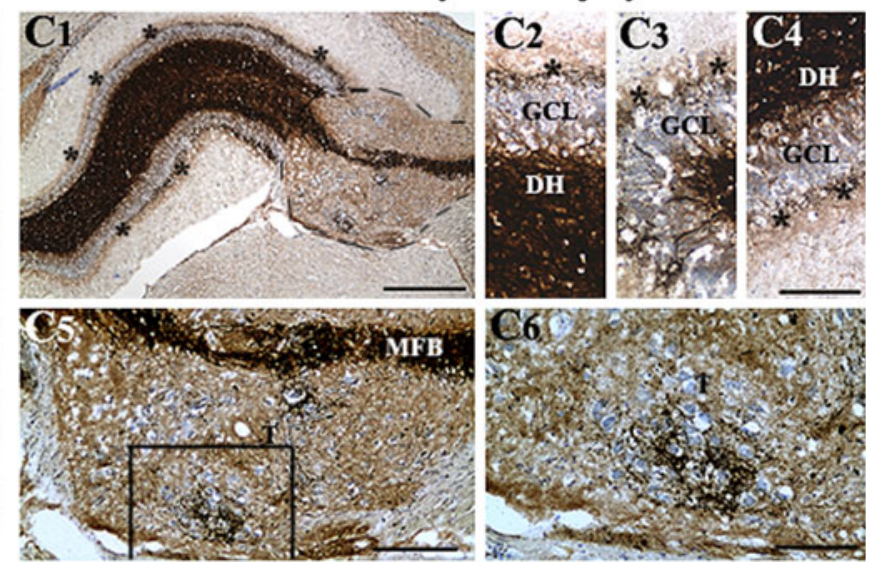

(CA3) region. Figures in (C2-C4) are regions from the upper blade, the crest, and the lower blade of the dentate gyrus (C1) and show minimal aberrant mossy fiber sprouting into the DSGL (black asterisks). (C5) Illustrates the innervation of the transplant by host mossy fibers. (C6) Enlarged view of the boxed region in (C5) of the transplant in shows clusters (CA3) of pyramidal neurons surrounded by mossy fiber terminals. $\mathrm{DH}=$ dentate hilus; $\mathrm{GCL}=$ granule cell layer; $\mathrm{Hps}=$ hippocampus; $\mathrm{KA}=$ kainic acid; $\mathrm{MFB}=$ mossy fiber bundle; $\mathrm{T}=$ transplant. Scale bars $=(\mathrm{A} 1, \mathrm{~B} 1, \mathrm{C} 1) 500 \mu \mathrm{m}$; (A2, B2B4, C2-C4, C6) $100 \mu \mathrm{m}$; (C5) $200 \mu \mathrm{m}$. (Figure reproduced with modifications from (Fig. 1), Shetty et al., J Neurosci 2005;25:83918401)

hippocampal precursor cells into the neurons $(91 \%$ of surviving cells), GABA-ergic interneurons (16\%), and CA3 pyramidal neurons (19\%). In comparison to hippocampi of rats that underwent SE alone, hippocampi of rats that underwent SE and received hippocampal cell grafts exhibited minimal aberrant mossy fiber sprouting, a significant preservation of calbindin in dentate granule cells, and increased numbers of neuropeptide Y (NPY) and parvalbumin $(\mathrm{PV})$ positive interneurons. These beneficial effects observed after hippocampal cell grafting were specific to the presence of grafted hippocampal cells, as grafting of nonspecific cerebellar cells or sham-grafting surgery did not impede the SE-induced robust chronic epilepsy development [45]. Additional studies showed that grafting of hippocampal precursor cells as previously described considerably eased the spatial learning and memory deficits that are typically associated with SEinduced TLE [46].

\section{Efficacy of Grafts of GABA-Producing Cells for Diminishing SE- or Kindling-Induced SRS}

It is believed that an increased excitatory neurotransmission found in the epileptic hippocampus is partly due to a reduced number of GABA-ergic interneurons $[8,9]$, loss of functional inhibition [47-49], and diminished numbers of 
GABA-ergic terminals $[50,51]$. From this perspective, the idea of restraining SRS in the epileptic hippocampus via grafting of cells that just release the inhibitory neurotransmitter GABA at seizure foci has received much attention [28]. Accordingly, the efficacy of grafting of different GABA-producing cells into different regions of the brain for restraining SRS has been evaluated in several models of TLE. Bilateral grafting of conditionally immortalized neurons engineered to produce GABA into the substantia nigra of rats at 45 to 65 days after SE resulted in fewer SRS at 1 to 10 days postgrafting in comparison to the SE group that received only control cells [52], suggesting that grafting of cells that simply produce GABA can also diminish SRS if grafted into the seizure-modulating nucleus. Several other studies have also examined the effects of grafting of GABA-producing cells into the dentate gyrus or the substantia nigra on SRS in both kindling and SE models [53-57]. Transplantation of these cells were associated with increased GABA levels, enhanced local electrical seizure threshold, and delayed onset of behavioral SRS in the kindling model of epilepsy [53] and diminished extent of seizures in SE models $[55,56]$.

Although these results are interesting and provide a proof of principle for suppressing SRS using GABAproducing cells, it is unknown whether cells engineered to produce GABA are capable of exhibiting enduring survival and maintaining GABA release on a long-term basis in the epileptic brain. From this perspective, grafting of GABAergic precursor neurons appears attractive for long-term functional recovery, as these cells can be obtained from discrete regions (such as the medial and lateral ganglionic eminences) of the fetal brain. Indeed, a study has demonstrated that bilateral grafting of GABA-ergic striatal precursor cells pre-treated with fibroblast growth factor (FGF)-2 and caspase inhibitor into hippocampi at 4 days post-SE is efficacious for diminishing SE-induced chronic epilepsy through long-term survival and differentiation into GABA-ergic neurons [58]. Analyses at 9 to 12 months postgrafting revealed that the overall frequency of behavioral SRS was 67 to $89 \%$ less than that observed in SE rats that underwent sham-grafting surgery and SE rats that received neither grafts nor sham-grafting surgery (Fig. 4). Graft cell survival was $\sim 33 \%$ of injected cells and $\sim 69 \%$ of surviving cells differentiated into GABA-ergic interneurons (Fig. 5), which comprised subclasses expressing calbindin, PV, calretinin, and NPY. Grafting also preserved hippocampal calbindin but had no effects on the aberrant mossy fiber sprouting in the dentate gyrus.

Thus, grafting of appropriately treated striatal precursor cells into hippocampi shortly after SE is proficient for greatly reducing SRS on a long-term basis in the chronic epilepsy period. Presence of a large number of GABA-ergic neurons in grafts further suggested that strengthening of the

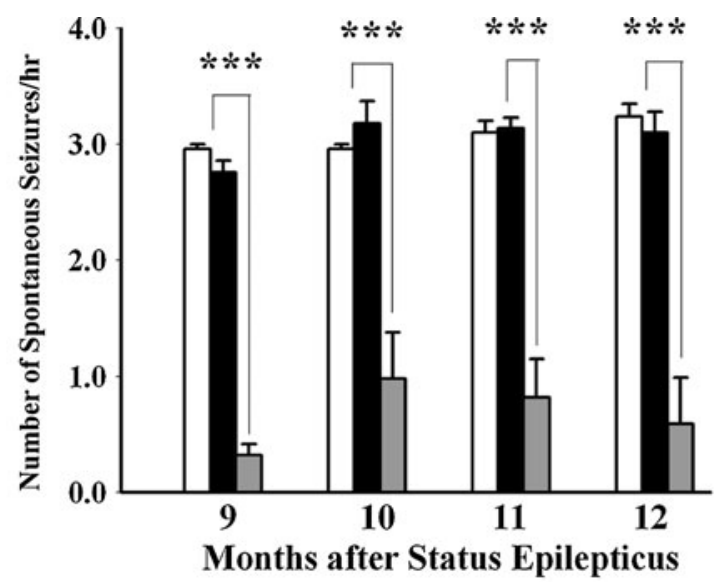

\footnotetext{
$\square=$ Rats that underwent SE alone

= Rats that underwent SE and Sham Surgery

$=$ Rats that underwent $\mathrm{SE}$ and received Striatal Precursor Cell Grafts $* * *=\mathbf{p}<0.001$
}

Fig. 4 Effects of striatal precursor cell grafting shortly after status epilepticus (SE) on the extent of chronic epilepsy. The bar chart illustrates the frequency of spontaneous recurrent motor seizures (SRMS) at 9 to 12 months post-SE in different groups of rats that underwent SE. Values in different groups represent means and standard errors. Both rats receiving no grafts (i.e., epilepsy-only rats, $\mathrm{n}=5)$ and rats receiving sham grafting surgery $(\mathrm{n}=5)$ exhibit $\sim 3.0$ SRMS/h during this period. In sharp contrast, epileptic rats receiving striatal precursor cell grafts (treated with fibroblast growth factor-2 and a caspase inhibitor Ac-YVAD-cmk, $n=5$ ) exhibit considerably diminished frequency of SRMS during this period. Overall, there was 67 to $89 \%$ decrease in seizure frequency in the grafted group in comparison to epilepsy-only and sham grafting surgery groups $(* * *<0.001)$. (Figure reproduced with modifications from (Fig. 2), Hattiangady et al., Exp Neurol 2008;212:468-481)

inhibitory control in the host hippocampus likely underlies the beneficial effects mediated by grafts. Consistent with these findings, a study has shown that grafting of GABAergic precursor cells from the medial ganglionic eminence (MGE) into the hippocampi of mutant postnatal mice lacking a shaker-like potassium channel (Kv1.1./Kcna1; mimicking a neuronal ion channelopathy associated with epilepsy in humans) greatly reduces both frequency and duration of spontaneous EEG seizures [59]. Likewise, a recent study has shown restoration of the hippocampal inhibitory function with grafting of MGE-derived GABAergic precursor cells in a mouse prototype of seizure susceptibility, induced through an injection of the neurotoxic saproin conjugated to substance P [60].

\section{Effects of Grafts of Adenosine-Producing Cells for Reducing Kindling or SE-Induced SRS}

In addition to grafting of GABA-producing cells, a succession of investigations have ascertained the outcome of grafts of encapsulated fibroblasts engineered to release 
Fig. 5 Differentiation of grafted striatal precursor cells into neurons and $\gamma$-aminobutyric acid (GABA) positive neurons. (A1-A3) Examples of 5'bromodeoxyuridine (BrdU)-positive grafted cells that differentiated into neuron-specific nuclear antigen (NeuN) positive neurons (arrows) using BrdU and NeuN dual immunofluorescence. (A4-A8) Illustrates Zsection analyses of grafted cells that are positive both BrdU and NeuN, using confocal microscopy. (B1-B3) Examples of grafted cells that are differentiated into GABA-positive neurons (arrows) using BrdU and GABA dual immunofluorescence. (B4-B8) Illustrates Zsection analyses of a grafted cell that is positive for both $\mathrm{BrdU}$ and GABA using confocal microscopy. (C1) Bar chart depicts average numbers of BrdUpositive cells, NeuN-positive neurons, and GABA-ergic neurons derived from individual striatal precursor cell grafts in the hippocampus. (A1-A3, B1B3 $)=20 \mu \mathrm{m} ;($ A4-A8, B4-B8) $=$ $10 \mu \mathrm{m}$. (Figure reproduced with modifications (Fig. 5), from Hattiangady et al., Exp Neurol $2008 ; 212: 468-481)$
Differentiation of grafted cells int $\mathrm{NeuN}+$ neurons
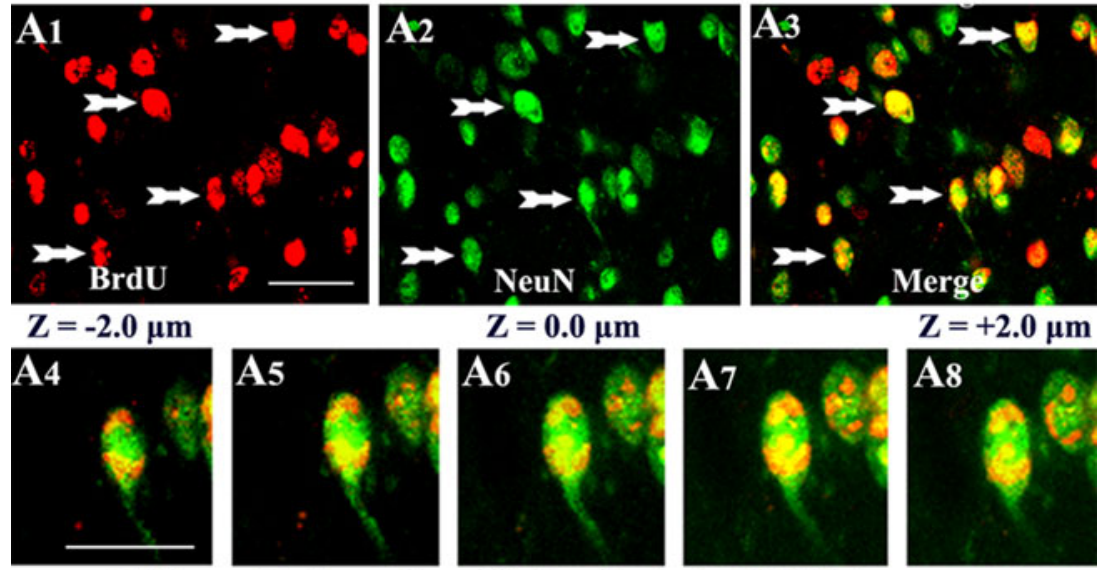

$\mathrm{Z}=\mathbf{0 . 0} \boldsymbol{\mu m}$

$\mathrm{Z}=+\mathbf{2 . 0} \mu \mathrm{m}$
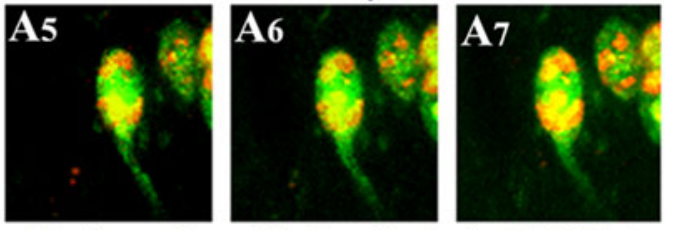

A8

Differentiation of grafted cells into GABA+ neurons
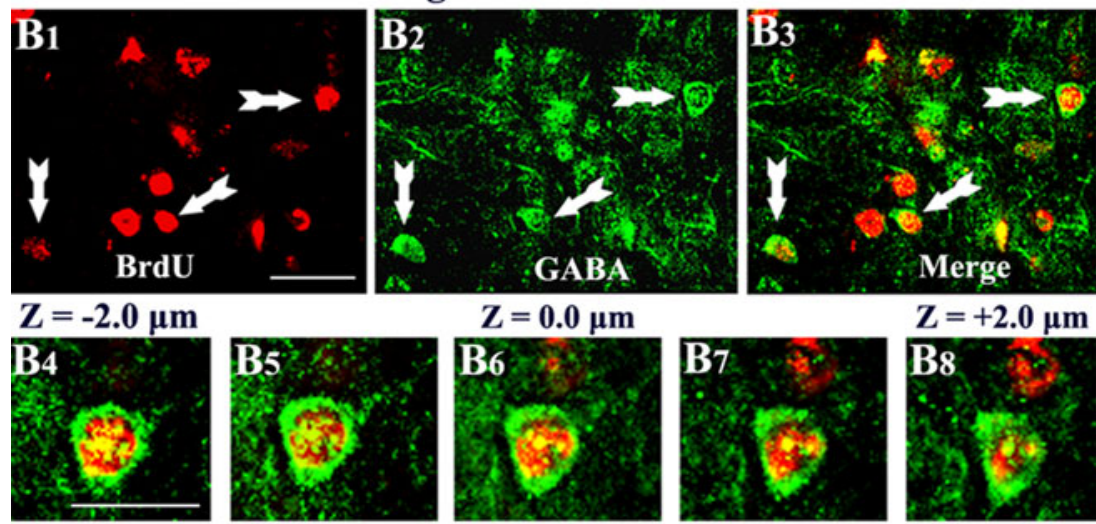

$\mathrm{Z}=\mathbf{0 . 0} \boldsymbol{\mu m}$
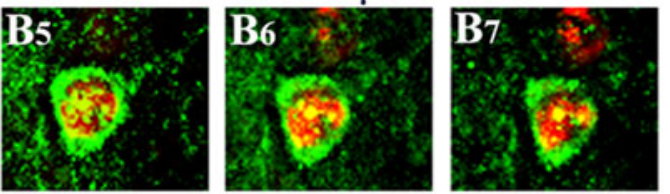

$\mathrm{Z}=+\mathbf{2 . 0} \mu \mathrm{m}$

C1

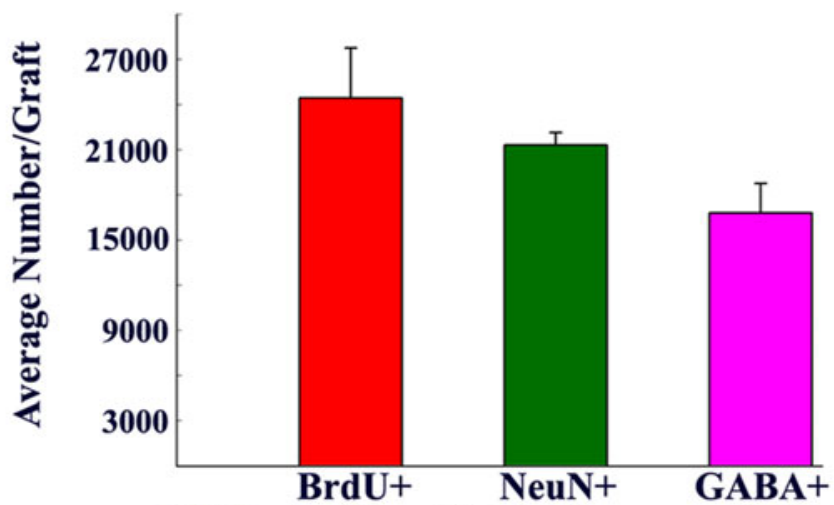

Cells Derived from Striatal Precursor Cell Grafts the brain's endogenous anticonvulsant adenosine on SRS [61-64]. In standard conditions, adenosine is produced by the astrocytes. However, in epileptic environments because of the upregulation of the adenosine kinase the concentration of adenosine is greatly reduced in the hippocampus. An initial study reported that grafting of these cells into the brain ventricles of rats kindled in the hippocampus induces temporary reductions (lasting $\sim 2$ weeks) in behavioral SRS and after discharges. The use of mouse myoblasts engineered to release adenosine also revealed similar transient suppressing effects on SRS in $\sim 50 \%$ of animals [65]. The ephemeral nature of helpful effects in these studies insinuated that either the grafted cells fail to exhibit enduring survival in an ectopic location or the quantity of adenosine released by these cells becomes scarce with the passing of time. Grafting of embryonic stem (ES) cellderived neural precursors that are engineered to release adenosine through biallelic genetic disruption of the adenosine kinase gene (Adk-/-), however, resulted in sustained protection against developing generalized SRS 
in a kindling model of TLE [66] and suppression of SRS in mice when grafted after the epileptogenesis-precipitating brain injury [67]. These results are indeed promising for future development of stem cell-mediated adenosine delivery for treating TLE. However, it remains to be validated whether cells engineered to release adenosine have the ability to deliver adequate amount of adenosine on a permanent basis in chronic epileptic conditions, as such delivery is not likely to be dependent on the synaptic activity of neurons. Hence, it will be vital to scrupulously investigate the practicality of these grafts placed into the brain of animals exhibiting chronic SRS. Additionally, it is unknown whether the extent of seizure suppression mediated through increased concentrations of adenosine would be sufficient for reversing cognitive and mood dysfunction seen in chronic TLE.

\section{Efficacy of Grafts of Neural Stem Cells for Easing Injury or SE-Induced SRS}

NSCs are attractive for use as donor cells for grafting in TLE because these cells can be expanded in culture for extended periods from diverse sources, such as the fetal, postnatal, and adult brain human ES cells and human-induced pluripotent stem (iPS) cells [68-73]. The reasons for using NSC grafting therapy for suppressing SRS in TLE include their ability to: 1) migrate profusely into different cell layers of the hippocampus, 2) give rise to a sizable fraction of neurons synthesizing the inhibitory neurotransmitter GABA, and 3) generate astrocytes secreting the anticonvulsant factors such as the glial-derived neurotrophic factor (GDNF) [37, 74, 75]. In addition, NSC grafting has promise for easing cognitive and mood dysfunction seen in TLE, as NSCs can be a source of multiple neurotrophic factors that are capable of increasing the proliferation of endogenous NSCs and boosting the extent of net hippocampal neurogenesis [76], one of the substrates believed to be important for maintaining the hippocampal-dependent cognitive function and mood [77-81].

One of the earlier studies examined the efficacy of an intravenous administration of beta galactosidase-encoded $\left(\beta-\mathrm{gal}^{+}\right)$human NSCs at 1 day after the induction of SE for suppressing SRS [82]. Evaluation at 28 to 35 days post-SE revealed SRS in only $13 \%$ of rats that received NSC grafts after SE, in contrast to SRS in $87 \%$ of rats that underwent SE alone. Analyses of the field excitatory postsynaptic potentials in the CA1 subfield revealed smaller field excitatory postsynaptic potentials in rats that received NSC grafts after SE than rats that underwent SE alone. These functional effects were associated with the presence of variable numbers of $\beta$-gal ${ }^{+}$NSC graft-derived cells in multiple regions of the brain including the hippocampus and differentiation of some of the graft-derived cells into GABA and PV expressing interneurons. It is possible that the introduction of new GABA-synthesizing cells into the inhibitory circuitry of the injured hippocampus underlies the reductions in SRS in this study. In another study, NSCs obtained from the adult subventricular zone (SVZ)-NSCs were expanded in culture as neurospheres, and neurosphere cells were grafted into the rat hippocampus at 1 week after a hippocampal injury induced through a unilateral intracerebroventricular kainic acid administration [83]. This study showed that the KA-treated rats receiving NSC grafts exhibited reduced frequencies of abnormal spikes at 2 to 3 weeks postgrafting in comparison to the KA-treated rats receiving nonspecific grafts, implying that NSC grafting shortly after injury has the ability to decelerate the process of epileptogenesis. These effects were associated with improved survival of subclasses of host GABA-ergic interneurons and reduced aberrant sprouting of mossy fibers, which suggested that SVZ-NSC grafting after injury induces some anti-epileptogenic effects in the host. Furthermore, the frequency of abnormal spikes was found to be inversely proportional to the numbers of surviving graftderived cells, implying that a reduced frequency of abnormal spikes in grafted animals is linked to the presence of graft-derived cells. However, the possible differentiation of graft-derived cells into GABA-ergic interneurons and the effects of grafting on SRS were not evaluated.

A recent study investigated the efficacy of grafting of NSCs from the embryonic day 19 hippocampus (expanded as neurospheres in vitro) into hippocampi of adult rats at 1 week after the induction of SE for diminishing SRS in the chronic phase after SE [74]. To facilitate better survival and neuronal differentiation after grafting, the donor cells were treated and grafted with the neurotrophic factors FGF-2 and the brain-derived neurotrophic factor (BDNF). The results showed that rats receiving hippocampal NSC grafts after SE exhibited a considerably diminished frequency and intensity of behavioral SRS at 4 to 6 months postgrafting in comparison to rats that received sham-grafting surgery after SE $(82-90 \%$ reduction in all seizures and $89-93 \%$ reduction in stage-V seizures; $p<0.01$ ). Further evaluation of SRS at 6 months postgrafting using EEG recordings for 4 days demonstrated that grafting of NSCs is also efficacious for reducing the EEG seizures (53-63\% reduction in comparison to epilepsy-only and sham-grafted groups; $p<0.001$ ) in the chronic phase after SE [84]. Moreover, grafting of hippocampal NSCs after SE ameliorated the memory and mood dysfunction associated with SE-induced chronic epilepsy [84]. Histological analyses revealed pervasive migration of NSC graft-derived cells into different regions of the hippocampus and the overall yield of graft-derived cells was equivalent to $\sim 50 \%$ of the injected cells. 
Additional analyses demonstrated the ability of hippocampal NSCs to give rise to GABA-ergic neurons (equivalent to $\sim 15 \%$ of graft-derived cells) following grafting into the epileptic hippocampus and to exert a neuroprotective effect on the survival of host interneurons positive for the NPY and PV [84]. These properties likely underlie the diminished SRS and improved memory and mood function observed in rats that received NSC grafts after SE. Overall, the several beneficial effects shown with grafting of hippocampal NSCs in this study are relevant for the future clinical application of NSC grafting for restraining TLE development after a hippocampal injury inflicted through acute seizures, SE, stroke, or head injury.

\section{Cell Therapy for Easing Chronic TLE}

The patients with drug-resistant TLE are the most likely candidates for cell grafting therapy among the epilepsy patient population as an alternative to hippocampal resection surgery. Hence, it is important that graft-efficacy studies will need to be performed in prototypes where animals exhibit chronic epilepsy at the time of grafting. As seizures in TLE mainly originate from the hippocampus and are associated with cognitive impairments and reduced hippocampal neurogenesis, it is also important to examine the effects of cell transplantation into hippocampi of animals that exhibit not only SRS, but also cognitive impairments at the time of grafting intervention. The relevant graft efficacy studies performed so far are discussed as follows.

\section{Usefulness of Fetal Hippocampal Cell Grafts for Easing Chronic TLE}

A study by Rao et al. [26] investigated both survival and anti-seizure effects of embryonic day 19 fetal hippocampal cell (FHC) grafts pretreated with different neurotrophic factors and a caspase inhibitor. Grafts were placed bilaterally into the hippocampi of 3 groups of rats exhibiting kainate-induced chronic TLE, where the frequency of behavioral SRS varied from 0.38 to $0.44 / \mathrm{h}$. The first group received standard (untreated) FHC grafts, the second group received pretreated FHC grafts that were transplanted with (BDNF, neurotrophin-3 and caspase inhibitor [BNC] treated FHC grafts), and the third group received FHC grafts pretreated and transplanted with FGF2 and Ac-YVAD-cmk (FGF-2 and caspase inhibitor [FC] treated FHC grafts). A fourth group of rats with chronic epilepsy served as epilepsy-only controls. Epileptic rats receiving standard FHC grafts exhibited $119 \%$ increase in the frequency of behavioral SRS at 2 months postgrafting, consistent with the $125 \%$ increase in seizure frequency observed in epilepsy-only controls during the same period (Fig. 6). In contrast, in the epileptic rats receiving FHC grafts treated with BNC or FC, the frequency of behavioral SRS was 33 to $39 \%$ less than their pre-transplant scores and 73 to $76 \%$ less than rats receiving standard FHC grafts or epilepsy-only controls (Fig. 6). The yield of surviving neurons was equivalent to $30 \%$ of injected cells in standard FHC grafts, and 57 to $98 \%$ in FHC grafts treated with BNC or FC. Furthermore, rats receiving FHC grafts pretreated with either BNC or FC exhibited greater numbers of graftderived neurons and GABA-ergic inhibitory interneurons in hippocampi. Because the extent of damage to different hippocampal cell layers inflicted by the grafting procedure and the locations of grafts were similar in the 3 transplant groups, it appeared that diminished frequency of SRS observed in animals receiving BNC or FC-treated transplants is linked to the addition of a large number of new neurons (including GABA-ergic interneurons) from these grafts to chronically epileptic hippocampi. Taken together, this study provided the first evidence for the ability of

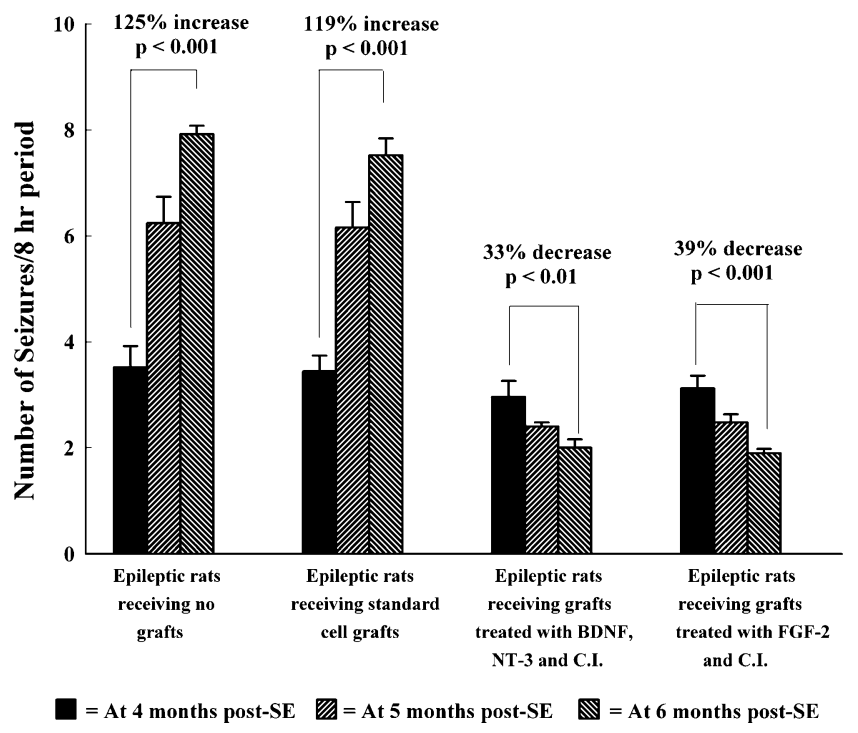

Fig. 6 Progression of the frequency of spontaneous recurrent motor seizures (SRMS) in different groups of chronically epileptic rats at 4 , 5 , and 6 months poststatus epilepticus (SE). Note that the in epileptic rats receiving no grafts and the epileptic rats receiving standard hippocampal fetal cell (HFC) grafts, the frequency of SRMS increases dramatically during this period. In contrast, in the epileptic rats receiving grafts treated with brain-derived neurotrophic factor (BDNF), neurotrophin-3 (NT-3), and caspase inhibitor (C.I.), or grafts treated with fibroblast growth factor (FGF)-2 and C.I., the frequency of SRMS declines significantly. Comparison of the frequency of SRMS between the different groups at 4, 5, and 6 months post-SE reveals that the frequency of SRMS in the epileptic rats was similar in all groups at 4 months post-SE. However, at 1 to 2 months postgrafting, the frequency of SRMS in rats receiving grafts treated with BDNF, NT-3, and C.I., or grafts treated with FGF-2 and C.I., is considerably less than the frequency observed in the epileptic rats receiving either no grafts or standard HFC grafts. (Figure reproduced with modifications (Fig. 2), from Rao et al., Neurobiol Dis 2007;27:117-132) 
appropriately treated FHC grafts to restrain behavioral SRS in a rat model of chronic TLE.

A follow-up study examined the long-term efficacy of FHC grafts treated with FC and placed bilaterally into the hippocampi of rats exhibiting robust (2.0-3.0/h) SRS [85]. Measurement of SRS through intermittent direct observation $(32 \mathrm{~h} /$ month) for 5 months after grafting uncovered progressive decreases in the frequency of behavioral SRS in rats receiving grafts. At 4 to 5 months postgrafting (equivalent to 9-10 months post-SE), the frequency of behavioral SRS was reduced to $11 \%$ of the frequency observed at the time of grafting. In contrast, in chronically epileptic rats receiving sham-grafting surgery and chronically epileptic rats receiving no surgery, the frequency of behavioral SRS at 9 to 10 months post-SE remained comparable to the frequency of SRMS observed at 5 months post-SE. Moreover, epileptic rats receiving FHC grafts exhibited $71 \%$ reduction in the duration of individual SRS. Short-term EEG recordings at 6 months postgrafting corroborated with the findings from behavioral SRS measurements. Graft analyses revealed robust long-term survival of grafted cells (with a recovery that is equivalent $\sim 81 \%$ of injected cells), and a majority $(95 \%)$ of grafted cells differentiated into neurons (and $\sim 10 \%$ into GABAergic inhibitory interneurons). Thus, grafting of FHCs treated with FC into the hippocampus was found to be highly efficacious for restraining SRS on a long-term basis in a rat model of chronic TLE.

\section{Efficacy of MGE Precursor Cell Grafts for Treating Chronic TLE}

The precursor cells from the MGE are one of the donor cell types that are being considered for treating chronic TLE with great interest. This is because the epileptic hippocampus exhibits an altered inhibitory function, and MGE is the source of most hippocampal GABA-ergic interneurons in the developing brain, and the observation that GABA-ergic interneurons derived from the MGE cells display ability for both functional integration and increasing the extent of inhibition when grafted into the normal postnatal brain [59, 86]. Therefore, a recent study examined the effects of grafting of freshly harvested MGE cells from gestation day 14 of rat brains into the hippocampi of rats exhibiting KAinduced chronic TLE typified by SRS and spatial memory dysfunction [87]. Quantitative measurements revealed a greatly reduced behavioral SRS in epileptic rats receiving MGE precursor cell grafts. The overall reductions in comparison to their pre-grafting seizure scores were $91 \%$ for the frequency of all SRS, $93 \%$ for the total percentage of time spent in SRS, and $100 \%$ for the frequency of stageV seizures. Additional comparison with the epilepsy-only group revealed that MGE precursor cell grafting greatly reduced both behavioral and EEG seizures. Analyses of spatial memory scores between the pre-grafting and postgrafting periods showed that MGE cell grafting eased the memory dysfunction seen before grafting. It was demonstrated that the grafts had a survival that is equivalent to $\sim 30 \%$ of injected cells and a migration pattern that is somewhat restricted to the immediate surrounding regions of the graft core. Furthermore, grafted cells differentiated into large numbers of GABA-ergic interneurons including the subclasses that are positive for NPY, somatostatin, and PV. Thus, grafting of MGE precursor cells into the hippocampi of rats exhibiting chronic TLE result in the addition of substantial numbers of GABA-ergic neurons, the reductions in both frequency and intensity of SRS, and an improved spatial memory function. However, the mechanisms underlying these functional effects are yet to be ascertained.

\section{Therapeutic Effects of Medial Ganglionic Eminence Neural Stem Cell Grafts in a Model of Chronic TLE}

A recent study examined the effects of grafting of NSCs expanded in vitro from the embryonic MGE into hippocampi (80,000 cells/graft; 4 grafts on each side) of adult rats exhibiting kainate-induced chronic TLE with cognitive impairments for $\sim 12$ months [37]. At 3 months after MGENSC grafting, the frequency of behavioral SRS was decreased by $43 \%$, the duration of individual SRS was reduced by $51 \%$, and the frequency of stage $\mathrm{V}$ seizures (the most severe form of SRS) was reduced by $90 \%$ (Fig. 7). However, sham grafting surgery had no effect on chronic epilepsy. Graft-derived cells migrated extensively into different layers of the CA3 subfield and the lateral regions of the CA1 and DG subfields throughout the anteroposterior axis of the hippocampus. Quantification of the total numbers of graft-derived cells demonstrated a yield that was equivalent to $28 \%$ of injected cells or $\sim 81,536$ cells per hippocampus. Extrapolation of the yield of graft-derived cells with percentages of different phenotypes suggested that MGE-NSC grafting resulted in addition of more than 10,000 new neurons, 46,000 new astrocytes, 2,000 new oligodendrocyte progenitors and 8,000 new GABA-ergic neurons into each hippocampus of chronically epileptic rats. A substantial fraction $(\sim 50 \%)$ of cells derived from the MGE-NSC grafts also expressed the GDNF, which morphologically appeared to be astrocytes. This resulted in addition of more than 40,000 new GDNF + cells into each hippocampus of the epileptic rats. Furthermore, MGE-NSC grafting restored GDNF expression in the host hippocampal astrocytes.

A significant suppression of SRS by NSC grafts appeared to be due to both additions of GABA-ergic 
Fig. 7 Long-term effects of medial ganglionic eminence (MGE)-neural stem cell (NSC) grafting (a-d) on spontaneous recurrent motor seizures (SRMS) in chronically epileptic rats. The Y-axis in bar charts (a) and (c) denotes the average numbers of seizures per session (4-h block) of observation. Note that MGE-NSC grafting considerably decreases the seizure frequency (a), the duration of individual seizures (b), the severity of seizures (c), and the total time spent in seizures (d). ${ }^{*} p<0.05 ;{ }^{* *} p<0.01$. (e, f) The bar charts show seizure frequency and seizure duration in chronically epileptic animals that received sham-grafting surgery. Sham-grafting surgery does not alter the seizure frequency or the seizure duration in chronically epileptic rats. (Figure reproduced with modifications (Fig. 3), from Waldau et al., Stem Cells 2010;28:11531164)
Effects of MGE-NSC Grafting on SRMS
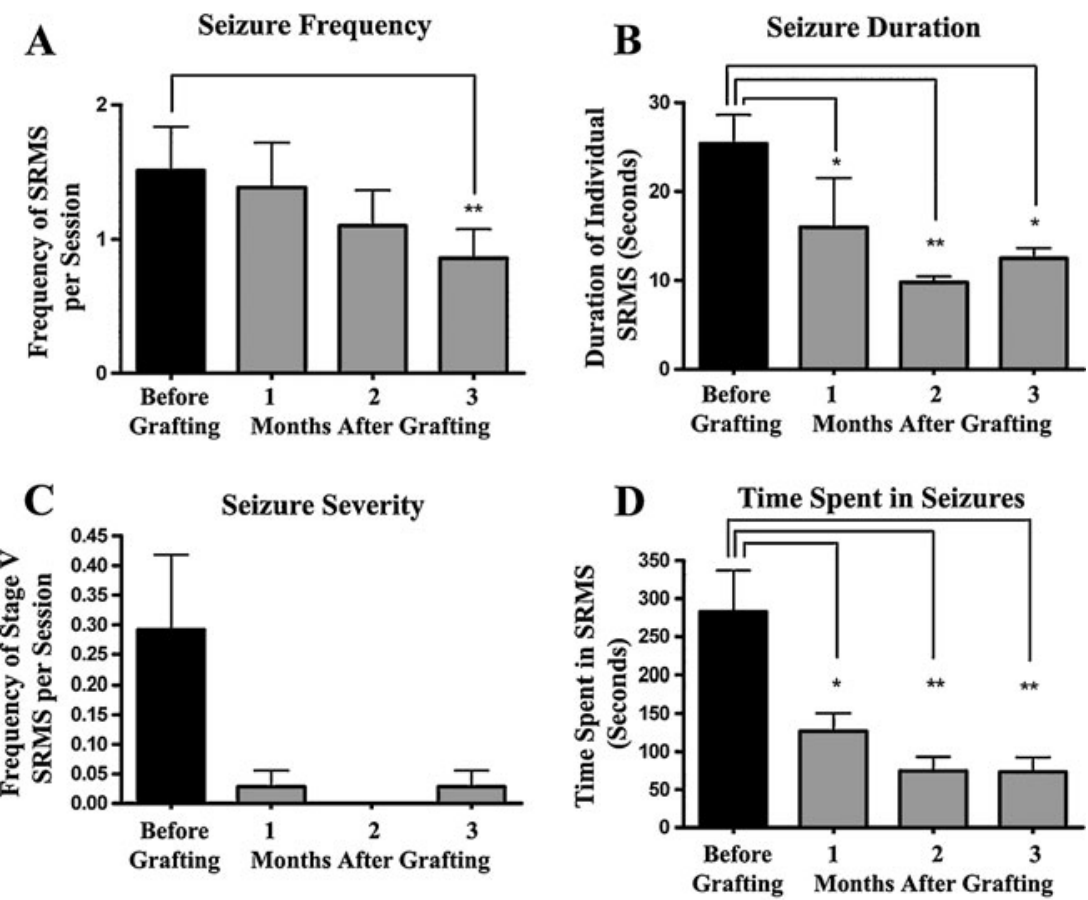

Effects of Sham-Grafting Surgery on SRMS

E

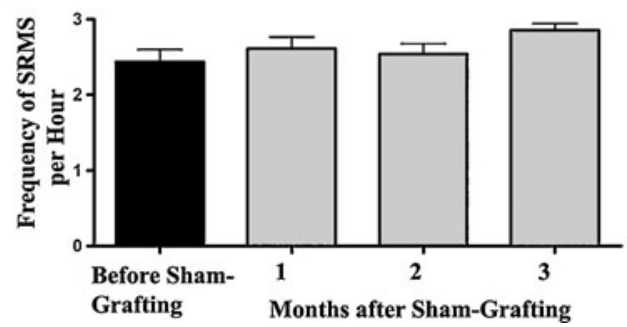

F

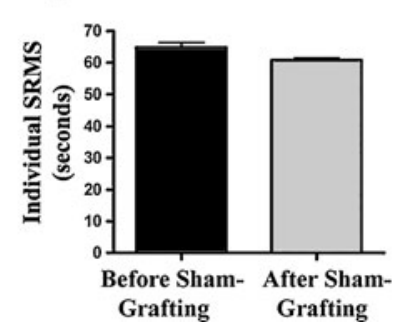

neurons and GDNF secreting cells, and restoration of the GDNF expression in the host hippocampal astrocytes. This is because: 1) GABA-ergic function is reduced in TLE [6, $8,9,15,48]$; 2) grafting of cells that just release GABA can facilitate transient anti-seizure effects [28, 29, 53, 56, 88]; 3) axons of GABA-ergic neurons derived from the MGE cell grafts exhibit a high propensity for increasing the extent of inhibition in the normal postnatal brain $[59,86]$; and 4) increased GDNF levels in the epileptic brain restrain SRS [89, 90]. However, rigorous electrophysiological, electron-microscopic, and biochemical studies are needed in the future to confirm these possibilities. Transplantation of the MGE-NSC grafts did not reverse the hippocampaldependent spatial learning and memory deficits; however, this could be due to the fact that MGE-NSC grafting did not improve hippocampal neurogenesis, which is a substrate believed to be important for hippocampal-dependent learning and memory function [78-81], and exhibits a substantial decline in chronic TLE [91, 92]. Furthermore, MGE-
NSC grafting did not result in the replacement of the lost CA1 or CA 3 pyramidal neurons in the host hippocampus. It is possible that restoration of the cognitive function may need a much higher level of seizure suppression than what was observed in this study. Additionally, grafting of NSCs that are capable of substantially enhancing the extent of hippocampal neurogenesis via both engraftment into the neurogenic region and stimulation of the endogenous NSCs (Hattiangady et al., [76] in 2007) or grafting of cells that have the ability to differentiate into hippocampal pyramidal neurons and restore the damaged CA1-CA3 circuitry [8, 14, 26] may also be helpful. Overall, this study provided novel evidence that grafting of MGE-NSCs into the hippocampi is a promising approach for suppressing SRS in chronic TLE. However, additional strategies for improving: 1) the yield of graft-derived GABA-ergic neurons, 2) the overall seizure suppression; and 3) the hippocampal neurogenesis and cognitive function, will need to be developed prior to any clinical application of this strategy. 


\section{Efficacy of ES Cell-Derived NSC Grafts for Easing Chronic TLE}

A recent study has examined the effectiveness of grafting NSCs originated from the mouse ES cells into the hippocampus of kindled epileptic mice displaying the stage $\mathrm{V}$ seizures for controlling SRS [75]. Assessment of SRS at 6 weeks following the grafting through behavioral surveillance revealed a partial recovery from seizures in all animals that received NSC grafts. The improvement was however demonstrated only in terms of decreases in the intensity of seizures (i.e. from the stage $\mathrm{V}$ seizure to the stage III/IV seizure) but was significant in comparison to the shamoperated rats presenting the stage $\mathrm{V}$ seizures through the equivalent time period. Qualitative immunohistochemical analyses showed some differentiation of the graft-derived cells into neurons including neurons that are positive for the GABA synthesizing enzyme GAD-67. Even though this study provided the suggestion that NSCs derived from the ES cells are also useful for restraining SRS in a TLE model, there are quite a few drawbacks in this study. These include: 1) short discontinuous investigations of SRS (i.e., at 2, 4, and 6 weeks after the grafting); 2) no EEG recordings to document all SRS occurring in the entire postgrafting observation period; and 3) no quantitative correlation between the phenotype of the NSC graft-derived cells (such as cells positive for GAD-67) and SRS.

\section{Conclusions and Future Directions}

After reviewing grafting studies that have been conducted so far in animal models of TLE, the emerging conclusions are that cell therapy pertaining to epilepsy has 2 major goals. One of the goals is to use grafting intervention as a prophylaxis against chronic epilepsy development after an IPI. The other goal is to use grafting for containing SRS and improving cognitive function after the occurrence of chronic TLE.

The occurrence of SRS in the chronic phase after insults, such as SE or head injury, is believed to be due to both hippocampal neurodegeneration and multiple epileptogenic changes that ensue in the hippocampus after injury. The evolution into a chronic TLE state progressively occurs after an IPI. Hence, interventions that are efficacious for blocking or greatly reducing the epileptogenic processes have great significance for reducing the likelihood of developing chronic TLE after a hippocampal injury occurring from causes such as SE, stroke, and traumatic brain injury. Indeed, several cell grafting approaches into the hippocampus shortly after an IPI have shown considerable efficiency for diminishing the frequency and intensity of SRS and cognitive dysfunction in the chronic phase after an IPI. Nonetheless, there is no proof so far to support that neural cell grafting after an IPI can effectively prevent the occurrence of chronic
TLE. Hence, clinical application of neural cell grafting as a prophylaxis against chronic epilepsy development after an IPI is not recommended at this time. Rigorous analyses of anti-epileptogenic effects of diverse donor cell types that are easily accessible will be needed in IPI models of TLE. The donor cells may include hippocampal precursor cells, GABA-ergic progenitors, and NSCs obtained from diverse sources, including the human ES cells and the human iPS cells, as the technology for generating such cells from these sources is currently being developed [93, 94]. The use of such cells would also prevent the dependency on human fetal derived cells, which are difficult to obtain in sufficient quantities required for grafting, and their use is also restrained because of ethical concerns [25].

On the other hand, neural cell grafting treatment may be suitable for restraining SRS in chronic TLE patients. This is particularly true for intractable TLE because the available treatment options, such as AED intake, VNS, and ketogenic diet are ineffective and have considerable side effects. The option of hippocampal resection surgery may not be feasible for all patients with intractable TLE and may result in severe cognitive dysfunction. To date, grafting of several cell types (e.g., fetal hippocampal precursor cells, MGE precursors, and MGE-NSCs) has shown considerable efficacy for restraining SRS when applied shortly or at prolonged periods after the onset of TLE in animal models. Although precise mechanisms by which neural cell grafts mediate seizure suppression are unknown, correlative analyses in different studies suggest that neural cell grafting: 1) adds, substantial numbers of the GABA-ergic interneurons and GDNF-secreting cells (likely astrocytes) into the epileptic host hippocampus [37]; 2) induces the reactivation of the host hippocampal GABA-ergic interneurons [8]; 3) facilitates the restoration of the GDNF expression in the host hippocampal astrocytes [37]; and 4) diminishes the aberrant mossy fiber sprouting in the dentate gyrus [36]. In this context, an earlier Food and Drug Administration-approved study of porcine fetal GABAergic cell xenografts in 3 patients with AED-resistant partial epilepsy showing efficacy for seizure suppression is very relevant $[28,95]$. Although the porcine to human xenografting clinical trials had to be halted by the Food and Drug Administration because of the potential risk of porcine derived retroviruses, the results of this human study and the several recent studies in animal models of chronic TLE do support the use of apt GABA-ergic progenitors for treating drug-resistant TLE in the near future. However, additional rigorous studies are needed to reach the stage of clinical trials. Such studies should examine the efficacy of hippocampal and GABA-ergic progenitors, as well as NSCs derived from sources, such as human ES cells and human iPS cells for enduring survival and ability to generate significant numbers of GABA-ergic 
interneurons and GDNF-secreting astrocytes after grafting into the hippocampus in animal models that exhibit SRS for prolonged periods prior to the grafting intervention. Such an animal prototype would be critical for these studies to simulate the scenario in drug-resistant epilepsy. Furthermore, assessment of seizure suppression using continuous video EEG analyses for months after grafting will be required to rigorously gauge the anticonvulsant properties of distinct grafts on a long-term basis. Additionally, it will be important to determine whether the synaptic integration of graft-derived GABA-ergic interneurons underlies the suppression of SRS. This should also include evaluation of the effects of graftderived GABA-ergic interneurons on host brain activity at both cellular and network levels [96]. Although a clear demonstration of the efficacy may be adequate for a treatment to be approved by the Food and Drug Administration, comprehending the mechanisms of seizure suppression mediated by different grafts will be important for further improving the overall therapeutic benefit of grafts.

Another issue that may emerge is that some grafting strategies might suppress SRS via increased inhibition, but may fail to improve the cognitive and mood function in chronic TLE [37]. From this perspective, application of combined strategies may be considered. This may include grafting of neural cells (hippocampal or MGE progenitors or NSCs) into the hippocampus with: 1) systemic administration of hippocampal neurogenesis-enhancing factors such as neurotrophic factors, antidepressants, antioxidants, dietary supplements, or small molecules; and 2) NSCs that are engineered to release neurogenesis enhancing factors. Furthermore, developing strategies that are proficient for enhancing the overall yield of graft-derived GABA-ergic interneurons and GDNF secreting cells, the connectivity of graft-derived GABA-ergic interneurons, and the engraftment of graft-derived NSCs into the neurogenic region of the hippocampus to restore the greatly waned hippocampal neurogenesis observed in chronic TLE [91, 92] will be helpful.

Acknowledgments This work was supported by grants from the National Institute of Neurological Disorders and Stroke (RO1 NS054780) and the Department of Veterans Affairs (VA Merit Award). The author thanks Drs. B. Hattiangady, M.S. Rao, V. Zaman, B. Waldau, R. Kuruba, and B. Shuai for their excellent contributions to the grafting studies in epilepsy models performed in Shetty Laboratory at the Duke University Medical Center and the Durham Veterans Affairs Medical Center.

Author declares no real or perceived conflict of interest. Full conflict of interest disclosure is available in the electronic supplementary material for this article.

\section{References}

1. French JA, Williamson PD, Thadani VM, et al. Characteristics of medial temporal lobe epilepsy: I. Results of history and physical examination. Ann Neurol 1993;34:774-780.
2. McNamara JO. Emerging insights into the genesis of epilepsy. Nature 1999;399:A15-A22.

3. Lewis DV. Losing neurons: selective vulnerability and mesial temporal sclerosis. Epilepsia 2005;46(suppl 7):39-44.

4. Manford M, Hart YM, Sander JW, Shorvon SD. National General Practice Study of Epilepsy: partial seizure patterns in a general population. Neurology 1992;42:1911-1917.

5. Strine TW, Kobau R, Chapman DP, Thurman DJ, Price P, Balluz LS. Psychological distress, comorbidities, and health behaviors among U.S. adults with seizures: results from the 2002 National Health Interview Survey. Epilepsia 2005;46:11331139.

6. de Lanerolle NC, Kim JH, Robbins RJ, Spencer DD. Hippocampal interneuron loss and plasticity in human temporal lobe epilepsy. Brain Res 1989;495:387-395.

7. Engel J Jr. Mesial temporal lobe epilepsy: what have we learned? Neuroscientist 2001;7:340-352.

8. Shetty AK, Turner DA. Fetal hippocampal CA3 cell transplants restore host hippocampal GAD-positive interneuron numbers in a rat model of TLE. J Neurosci 2000;20:8788-8801.

9. Shetty AK, Turner DA. Glutamic acid decarboxylase positive hippocampal interneurons undergo a permanent reduction in number following kainic acid induced destruction of CA3 pyramidal neurons. Exp Neurol 2001;176:276-297.

10. Pitkanen A, Sutula TP. Is epilepsy a progressive disorder? Prospects for new therapeutic approaches in temporal-lobe epilepsy. Lancet Neurol 2002;1:173-81.

11. Kobayashi M, Buckmaster PS. Reduced inhibition of dentate granule cells in a model of temporal lobe epilepsy. J Neurosci 2003;23:2440-2452.

12. Detour J, Schroeder H, Desor D, Nehlig A. A 5-month period of epilepsy impairs spatial memory, decreases anxiety, but spares object recognition in the lithium-pilocarpine model in adult rats. Epilepsia 2005;46:499-508.

13. Devinsky O. Therapy for neurobehavioral disorders in epilepsy. Epilepsia 2004;45(S2):34-40.

14. Shetty AK, Zaman V, Hattiangady B. Repair of the injured adult hippocampus through graft-mediated modulation of the plasticity of the dentate gyrus in a rat model of temporal lobe epilepsy. J Neurosci 2005;25:8391-8401.

15. Shetty AK, Hattiangady B, Rao MS. Vulnerability of hippocampal GABA-ergic interneurons to kainate induced excitotoxic injury during old age. J Cell Mol Med 2009;13(8B):2408-2423.

16. Dudek FE, Sutula TP. Epileptogenesis in the dentate gyrus: a critical perspective. Prog Brain Res 2007;163:755-773.

17. Litt B, Esteller R, Echauz J, et al. Epileptic seizures may begin hours in advance of clinical onset: A report of five patients. Neuron 2001;30:51-64.

18. Astur RS, Taylor LB, Mamelak AN, et al. Humans with hippocampus damage display severe spatial memory impairments in a virtual Morris water task. Behav Brain Res 2002;132:77-84.

19. Vannest J, Szaflarski JP, Privitera MD, Schefft BK, Holland SK. Medial temporal fMRI activation reflects memory lateralization and memory performance in patients with epilepsy. Epilepsy Behav 2008;12:410-418.

20. Kossoff EH. The ketogenic diet: an appropriate first-line therapy? Expert Rev Neurother 2010;10:843-845.

21. Kossoff EH, Rho JM. Ketogenic diets: evidence for short- and long-term efficacy. Neurotherapeutics 2008;6:406-414.

22. Helmstaedter C. Temporal lobe resection-does the prospect of seizure freedom outweigh the cognitive risks? Nat Clin Pract Neurol 2008;4:66-67.

23. Vonck K, De Herdt V, Boon P. Vagal nerve stimulation-a 15-year survey of an established treatment modality in epilepsy surgery. Adv Tech Stand Neurosurg 2009;34:111-146. 
24. Shetty AK, Turner DA. Development of fetal hippocampal grafts in intact and lesioned hippocampus. Prog Neurobiol 1996;50:597653.

25. Turner DA, Shetty AK. Clinical prospects for neural grafting therapy for hippocampal lesions and epilepsy. Neurosurgery 2003;52:632-644.

26. Rao MS, Hattiangady B, Rai KS, Shetty AK. Strategies for promoting anti-seizure effects of hippocampal fetal cells grafted into the hippocampus of rats exhibiting chronic temporal lobe epilepsy. Neurobiol Dis 2007;27:117-132.

27. Shetty AK, Hattiangady B. Concise review: prospects of stem cell therapy for temporal lobe epilepsy. Stem Cells 2007;25:23962407.

28. Löscher W, Gernert M, Heinemann U. Cell and gene therapies in epilepsy - promising avenues or blind alleys? Trends Neurosci 2008;31:62-73.

29. Thompson K. Transplantation of GABA-producing cells for seizure control in models of temporal lobe epilepsy. Neurotherapeutics 2009;6:284-294.

30. Naegele JR, Maisano X, Yang J, Royston S, Ribeiro E. Recent advancements in stem cell and gene therapies for neurological disorders and intractable epilepsy. Neuropharmacol 2010;58:855864.

31. Eriksson PS, Perfilievam E, Bjork-Erikssonm T, et al. Neurogenesis in the adult human hippocampus. Nat Med 1998;4:13131317.

32. Abrous DN, Koehl M, Le Moal M. Adult neurogenesis: from precursors to network and physiology. Physiol Rev 2005;85:523569.

33. Parent JM, Yu TW, Leibowitz RT, Geschwind DH, Sloviter RS, Lowenstein DH. Dentate granule cell neurogenesis is increased by seizures and contributes to aberrant network reorganization in the adult rat hippocampus. J Neurosci 1997;17:3727-3738.

34. Scharfman HE, Goodman JH, Sollas AL. Granule-like neurons at the hilar/CA3 border after status epilepticus and their synchrony with area CA3 pyramidal cells: functional implications of seizureinduced neurogenesis. J Neurosci 2000;20:6144-6158.

35. Shetty AK, Zaman V, Turner DA. Pattern of long-distance projections from fetal hippocampal field CA3 and CA1 cell grafts in lesioned CA3 of adult hippocampus follows intrinsic character of respective donor cells. Neuroscience 2000;99:243-255.

36. Hattiangady B, Rao MS, Zaman V, Shetty AK. Incorporation of embryonic CA3 cell grafts into the adult hippocampus at 4months after injury: effects of combined neurotrophic supplementation and caspase inhibition. Neuroscience 2006;139:13691383.

37. Waldau B, Hattiangady B, Kuruba R, Shetty AK. Medial ganglionic eminence-derived neural stem cell grafts ease spontaneous seizures and restore GDNF expression in a rat model of chronic temporal lobe epilepsy. Stem Cells 2010;28:1153-1164.

38. Zaman V, Turner DA, Shetty AK. Survival of grafted fetal neural cells in kainic acid lesioned CA3 region of adult hippocampus depends upon cell specificity. Exp Neurol 2000;161:535-561.

39. Zaman V, Turner DA, Shetty AK. Prolonged post-lesion transplantation delay adversely influences survival of both homotopic and heterotopic fetal hippocampal cell grafts in Kainate-lesioned CA3 region of adult hippocampus. Cell Transplant 2001;10:4152.

40. Zaman V, Shetty AK. Fetal hippocampal CA3 cell grafts transplanted to lesioned $\mathrm{CA} 3$ region of the adult hippocampus exhibit long-term survival in a rat model of temporal lobe epilepsy. Neurobiol Dis 2001;8:942-52.

41. Buckmaster PS, Lew FH. Rapamycin suppresses mossy fiber sprouting but not seizure frequency in a mouse model of temporal lobe epilepsy. J Neurosci 2011;31:2337-2347.
42. Santhakumar V, Aradi I, Soltesz I. Role of mossy fiber sprouting and mossy cell loss in hyperexcitability: a network model of the dentate gyrus incorporating cell types and axonal topography. $\mathrm{J}$ Neurophysiol 2005;93:437-453.

43. Nägerl UV, Mody I, Jeub M, Lie AA, Elger CE, Beck H. Surviving granule cells of the sclerotic human hippocampus have reduced $\mathrm{Ca}(2+)$ influx because of a loss of calbindin-D(28 k) in temporal lobe epilepsy. J Neurosci 2000;20:1831-1836.

44. Rao MS, Hattiangady B, Reddy DS, Shetty AK. Hippocampal neurodegeneration, spontaneous seizures, and mossy fiber sprouting in the F344 rat model of temporal lobe epilepsy. J Neurosci Res 2006;83:1088-1105.

45. Hattiangady B, Rao MS, Kuruba R, et al. Efficacy of hippocampal precursor cell grafting early after status epilepticus for restraining epileptogenesis and chronic spontaneous seizures in a rat model of temporal lobe epilepsy. Soc Neurosci Abstr 2008;527:4.

46. Kuruba, R, Hattiangady B, Rao MS, Shetty AK. Hippocampal precursor cell grafting early after status epilepticus considerably attenuates learning and memory Dysfunction. Soc Neurosci Abstr 2008;527:2.

47. Lloyd KG, Bossi L, Morselli PL, Munari C, Rougier M, Loiseau $\mathrm{H}$. Alterations of GABA-mediated synaptic transmission in human epilepsy. Adv Neurol 1986;44:1033-1044.

48. Cornish SM, Wheal HV. Long-term loss of paired pulse inhibition in the kainic acid-lesioned hippocampus of the rat. Neurosci 1989;28:563-571.

49. During MJ, Ryder KM, Spencer DD. Hippocampal GABA transporter function in temporal-lobe epilepsy. Nature 1995;376:174-177.

50. Ribak CE, Hunt CA, Bakay RA, Oertel WH. A decrease in the number of GABAergic somata is associated with the preferential loss of GABAergic terminals at epileptic foci. Brain Res 1986;363:78-90.

51. Esclapez M, Trottier S. Changes in GABA-immunoreactive cell density during motor focal epilepsy induced by cobalt in the rat. Exp Brain Res 1989;76:369-385.

52. Thompson KW, Suchomelova LM. Transplants of cells engineered to produce GABA suppress spontaneous seizures. Epilepsia 2004;45:4-12.

53. Thompson KW. Genetically engineered cells with regulatable GABA production can affect after discharges and behavioral seizures after transplantation into the dentate gyrus. Neurosci 2005; 133:1029-1037.

54. Löscher W, Ebert U, Lehmann H, Rosenthal C, Nikkhah G. Seizure suppression in kindling epilepsy by grafts of fetal GABAergic neurons in rat substantia nigra. J Neurosci Res 1998;51:196-209.

55. Castillo CG, Mendoza S, Freed WJ, Giordano M. Intranigral transplants of immortalized GABAergic cells decrease the expression of kainic acid-induced seizures in the rat. Behav Brain Res 2006;171:109-115.

56. Castillo CG, Mendoza-Trejo S, Aguilar MB, Freed WJ, Giordano M. Intranigral transplants of a GABAergic cell line produce longterm alleviation of established motor seizures. Behav Brain Res 2008;193:17-27.

57. Nolte MW, Löscher W, Herden C, Freed WJ, Gernert M. Benefits and risks of intranigral transplantation of GABA-producing cells subsequent to the establishment of kindling-induced seizures. Neurobiol Dis 2008;31:342-354.

58. Hattiangady B, Rao MS, Shetty AK. Grafting of striatal precursor cells into hippocampus shortly after status epilepticus restrains chronic temporal lobe epilepsy. Exp Neurol 2008;212:468-481.

59. Baraban SC, Southwell DG, Estrada RC, et al. Reduction of seizures by transplantation of cortical GABAergic interneuron precursors into Kv1.1 mutant mice. Proc Natl Acad Sci USA 2009;106:15472-15477. 
60. Zipancic I, Calcagnotto ME, Piquer-Gil M, Mello LE, AlvarezDolado M. Transplant of GABAergic precursors restores hippocampal inhibitory function in a mouse model of seizure susceptibility. Cell Transplant 2010;19:549-564.

61. Boison D. Adenosine and epilepsy: from therapeutic rationale to new therapeutic strategies. Neuroscientist 2005;11:25-36.

62. Boison D, Huber A, Padrun V, Deglon N, Aebischer P, Mohler H. Seizure suppression by adenosine-releasing cells is independent of seizure frequency. Epilepsia 2002;43:788-796.

63. Boison D, Scheurer L, Tseng JL, Aebischer P, Mohler H. Seizure suppression in kindled rats by intraventricular grafting of an adenosine releasing synthetic polymer. Exp Neurol 1999;160:164174.

64. Huber A, Padrun V, Deglon N, Aebischer P, Mohler H, Boison D. Grafts of adenosine-releasing cells suppress seizures in kindling epilepsy. Proc Natl Acad Sci USA 2001;98:7611-7616.

65. Guttinger M, Padrun V, Pralong WF, Boison D. Seizure suppression and lack of adenosine A1 receptor desensitization after focal long-term delivery of adenosine by encapsulated myoblasts. Exp Neurol 2005;193:53-64.

66. Li T, Steinbeck JA, Lusardi T, et al. Suppression of kindling epileptogenesis by adenosine releasing stem cell-derived brain implants. Brain 2007;130:1276-1288.

67. Li T, Ren G, Lusardi T, et al. Adenosine kinase is a target for the prediction and prevention of epileptogenesis in mice. J Clin Invest 2008;118:571-582.

68. Reynolds BA, Weiss S. Generation of neurons and astrocytes from isolated cells of the adult mammalian central nervous system. Science 1992;255:1707-1710.

69. Palmer TD, Markakis EA, Willhoite AR, Safar F, Gage FH. Fibroblast growth factor-2 activates a latent neurogenic program in neural stem cells from diverse regions of the adult CNS. J Neurosci 1999;19:8487-8497.

70. Zhang SC, Li XJ, Johnson MA, Pankratz MT. Human embryonic stem cells for brain repair? Philos Trans R Soc Lond B Biol Sci 2008;363:87-99.

71. Leonard BW, Mastroeni D, Grover A, et al. Subventricular zone neural progenitors from rapid brain autopsies of elderly subjects with and without neurodegenerative disease. J Comp Neurol 2009;515:269-294.

72. Saha K, Jaenisch R. Technical challenges in using human induced pluripotent stem cells to model disease. Cell Stem Cell 2009;5:584-595.

73. Yamanaka S. Patient-specific pluripotent stem cells become even more accessible. Cell Stem Cell 2010;7:1-2.

74. Kuruba R, Hattiangady B, Shuai B, Shetty AK. Effects of grafting of hippocampal stem/progenitor cells shortly after status epilepticus on the development of chronic epilepsy. Cell Transplant 2009;18:221-221.

75. Shindo A, Nakamura T, Matsumoto Y, et al. Seizure suppression in amygdala-kindled mice by transplantation of neural stem/progenitor cells derived from mouse embryonic stem cells. Neurol Med Chir 2010;50:98-105.

76. Hattiangady B, Shuai B, Cai J, Coksaygan T, Rao MS, Shetty AK. Increased dentate neurogenesis after grafting of glial restricted progenitors or neural stem cells in the aging hippocampus. Stem Cells 2007;25:2104-2117.

77. Sahay A, Hen R. Adult hippocampal neurogenesis in depression. Nat Neurosci 2007;10:1110-1115.

78. Dupret D, Revest JM, Koehl M, et al. Spatial relational memory requires hippocampal adult neurogenesis. PLoS ONE 2008;3: e1959.
79. Imayoshi I, Sakamoto M, Ohtsuka T, et al. Roles of continuous neurogenesis in the structural and functional integrity of the adult forebrain. Nat Neurosci 2008; 11:1153-1161.

80. Clelland CD, Choi M, Romberg C, et al. A functional role for adult hippocampal neurogenesis in spatial pattern separation. Science 2009;325:210-213.

81. Jessberger S, Clark RE, Broadbent NJ, et al. Dentate gyrus-specific knockdown of adult neurogenesis impairs spatial and object recognition memory in adult rats. Learn Mem 2009;16:147-154.

82. Chu K, Kim M, Jung KH, et al. Human neural stem cell transplantation reduces spontaneous recurrent seizures following pilocarpine-induced status epilepticus in adult rats. Brain Res 2004;1023:213-21.

83. Jing $M$, Shingo $T$, Yasuhara $T$, et al. The combined therapy of intrahippocampal transplantation of adult neural stem cells and intraventricular erythropoietin-infusion ameliorates spontaneous recurrent seizures by suppression of abnormal mossy fiber sprouting. Brain Res 2009;295:203-217.

84. Hattiangady B, Kuruba R, Parihar VK, Shetty AK. Intrahippocampal grafting of NSCs after status epilepticus eases both spontaneous seizures \& cognitive dysfunction in a rat model of temporal lobe epilepsy. Soc Neurosci Abstr 2010;29:30.

85. Hattiangady B, Rao MS, Rai KS, Zeng YC, Reddy DS, Shetty AK. Lasting inhibition of spontaneous recurrent motor seizures after hippocampal precursor cell grafting in rats exhibiting chronic temporal lobe epilepsy. Soc Neurosci Abstr 2006;280:4.

86. Hattiangady B, Shuai B, Parihar VK, Shetty AK. Medial ganglionic eminence precursor cell grafting diminishes spontaneous seizures and improves memory function in a rat model of temporal lobe epilepsy. Cell Transplant 2011;20:562-563.

87. Gernert M, Thompson KW, Löscher W, Tobin AJ. Genetically engineered GABA-producing cells demonstrate anticonvulsant effects and long-term transgene expression when transplanted into the central piriform cortex of rats. Exp Neurol 2002;176:183-192.

88. Alvarez-Dolado M, Calcagnotto ME, Karkar KM, et al. Cortical inhibition modified by embryonic neural precursors grafted into the postnatal brain. J Neurosci 2006;26:7380-7389.

89. Kanter-Schlifke I, Georgievska B, Kirik D, Kokaia M. Seizure suppression by GDNF gene therapy in animal models of epilepsy. Mol Ther 2007;15:1106-1113.

90. Kanter-Schlifke I, Fjord-Larsen L, Kusk P, Angehagen M, Wahlberg L, Kokaia M. GDNF released from encapsulated cells suppresses seizure activity in the epileptic hippocampus. Exp Neurol 2009;216:413-419.

91. Hattiangady B, Rao MS, Shetty AK. Chronic temporal lobe epilepsy is associated with severely diminished dentate neurogenesis in the adult hippocampus. Neurobiol Dis 2004;17:473-490.

92. Hattiangady B, Shetty AK. Decreased neuronal differentiation of newly generated cells underlies reduced hippocampal neurogenesis in chronic temporal lobe epilepsy. Hippocampus 2010;20:97-112.

93. Maisano X, Carpentino J, Becker S, et al. Embryonic stem cellderived neural precursor grafts for treatment of temporal lobe epilepsy. Neurotherapeutics 2009;6:263-277.

94. Maroof AM, Brown K, Shi SH, et al. Prospective isolation of cortical interneuron precursors from mouse embryonic stem cells. J Neurosci 2010;30:4667-4675.

95. Schachter SC, Schomer DL, Blume H, Ives JR, Joseph J. Porcine fetal GABA-producting neural cell grafts for human partial-onset seizures: safety and feasibility. Epilepsia 1998;39(supp 6);67.

96. Sebe JY, Baraban SC. The promise of an interneuron-based cell therapy for epilepsy. Dev Neurobiol 2011;71:107-117. 